\title{
AGR ADECIMIENTOS
}

Agradecemos vivamente las numerosas facilidades obtenidas y el cordial trato dispensadas por el Teniente Coronel J. Oliver, que nos ha permitido la realización de las campañas de herborización en la zona militar del Puig Major.

\section{BIBLIOGR AFIA}

BADRE, F. \& DESCHARTES, R. -1979- Les Ptéridophytes de la France, liste commentée des espèces. Taxonomie, cytologie, écologie et répartition générale. Candollea 34:379457.

BADRE, F. \& PRELLI, R. -1980- Additions à la flore pteridologique des Alpes Maritimes françaises. Riv. Sci. 9:5-25.

BOISSIER, E. -1838- Elenchus plantarum novarum minusque cognitarum, quas in itinere hispanico legit. Genevae.

FRASER-JENKINS, C.R. -1982- Dryopteris in Spain, Portugal and Macaronesia. Bol. Soc. Brot., ser. 2 55:175-336.

FRASER-JENKINS, C.R., REICHSTEIN, T. \& VIDA, G. -1975- Dryopteris tyrrhena nom. nov.- A misunderstood western mediterranean species. Fern. Gaz. 11:177-198.

MARCHETTI, D. -1984- Note Pteridologiche per la costa apezzina (Liguria Orientale). Boll. Mus. S. Nat. Lunig. 1:75-82.

MARCHETTI, D. -1985- Note floristiche Tosco-Liguri-Emiliane. III. Pteridofite interessanti della provincia della Spezia. Boll. Mus. S. Nat. Lunig 3:37-49.

NARDI, E. -1979- Commentaria pteridologica. III. Notulae chorolagicae atque cytologicae Italicae. Webbia 33:435-447.

PICHI-SERMOLLI, R.E.G. -1979- A survey of the pteridological flora of the Mediterranean Region, Webbia 34:175-242.

SALVO, A.E. \& ARRABAL, M.I. -1986- In S. Castroviejo et al. (Edit.): Flora Ibérica. Vol. 1: Lycopodiaceae-Papaveraceae. Real Jardín Botánico. Madrid.

(Aceptado para su publicación el 12 de enero de 1989)

Dirección de los autores: (1): Laboratorio de Botánica. Fac. de Ciencias. UI. Baleares, 07071 Palma de Mallorca. (2): Museu Balear de Ciencies Naturals, Camp d'En Prom, Sóller, Mallorca. (3) Departamento de Botánica. Fac. de Ciencias. 29080 Málaga.

\section{NOTAS PTERIDOLOGICAS DE GALICIA, III}

Francisco X. SOÑORA \& Santiago ORTIZ

Hymenophyllus tumbrigense (L.) Sm.

A CORUÑA: Santa Marta de Ortigueira, A Capelada, Landoi, Fraga do Nebril, en la cuenca del río Seixo, 29TNJ8739, 80 m s.n.m., 23-VIII-1988, X. Soñora \& E. Marín (SANT 18199); Santa Marta de Ortigueira, A Capelada, Outeiro, en la cuenca del río Lourido, 29TNJ8942, 100 m s.n.m., 21-X-1988, X. Soñora \& S. Ortíz (SANT 18202); Fene, en la cuenca del río Belelle, 29TNJ7114, 100 m s.n.m., 26-VIII-1988, X. Soñora \& E. Marín (SANT 18201). 
Tres nuevas localidades que indican que no es tan escaso en Galicia este pequeño helecho como, en principio, parecía, aunque todas estas citas se concentran en la misma cuadrícula occidental del subsector Galaico septentrional (sector Galaico-Asturiano). Su posición ecológica es siempre la misma: bosques umbríos de las cuencas fluviales con dirección norte o noroeste, pertenecientes al Blechno-Quercetum roboris pulmonarietosum longifoliae.

\section{Culcita macrocarpa K. Presl}

A CORUÑA: Santa Marta de Ortigueira, A Capelada, Landoi, Fraga do Nebril, restos del Blechno-Quercetum roboris pulmonarietosum longifoliae, en la cuenca del río Seixo, 29TNJ8739, 80 m s.n.m., 23-VIII-1988, X. Soñora \& E. Marín (SANT 18200).

Una nueva localidad gallega, cuarta peninsular, situada a unos $40 \mathrm{Km}$, en línea recta, de la tradicional de la Fraga de Caaveiro correspondiente a las citas de Laínz (Aport. con fl. gallega, VI:36. 1981) y Barrera (Os fentos de Galicia: 53. 1980). Respecto a esta última debemos apuntar que, en efecto, corresponde a la cuadrícula NJ4 igual que la inicial y no a la NH3 como aparece en el A.P.I.B. (Salvo \& al., Acta Bot. Malacitana, 9:116. 1984) debido, con seguridad, a una interpretación errónea de la referencia de Barrera (loc. cit.) que hace alusión al ayuntamiento de Monfero el cual incluye parte de la margen izquierda de la "Fraga" y no a las localidades con ese topónimo situadas a escasa distancia pero ya en la otra cuadrícula.

(Aceptado para su publicación el 2 de abril de 1989)

Dirección de los autores: Laboratorio de Botánica Departamento de Bioloxía Vexetal Facultad de Farmacia Universidad de Santiago E-15706 Santiago de Compostela

\section{SObRe DOS PTERIDOFITOS DEL MACIZO DE SEgURA-CAZORLA}

\section{Santiago PAJARON-SOTOMAYOR}

Ophioglossum vulgatum L.

JAEN, Benatae: Sierra de Segura, cerca de la Nava del Espino, 30SWH3739, 1300 $\mathrm{m}$, en prados inundados, suelo calcáreo, Pajarón 1421, 10-VI-1982; Hornos: cerca del Cortijo de la Fuente del Charco, 30SWH3126, 1450 m, en prados inundados, suelo calcáreo, J. López \& Pajarón 1176, 27-VI-1981.

Con estas recolecciones se confirma la presencia de esta especie en el macizo de Segura-Cazorla. De las referencias anteriores, el material recolectado por Heywood en El Campillo, Sierra de Segura, (MA 172778), localidad que recogen Galiano \& Heywood (1960: 14) y Salvo (1982: 138), corresponde a Ophioglossum azoricum C. Presl (López González, 1982: 524), y el material recolectado por Löve y Kjellqvist (1972: 27) en la Sierra de Cazorla, no hemos podido observarlo.

Cheilanthes crostica (Balbis) Tod.

JAEN, Hornos: Sierra de las Cuatro Villas, El Quijarón, 30SWH1727, 1150 m, en grietas de rocas calizas soleadas, Pajarón 1775 \& Rodríguez Pascual, 18-III-1988.

Nueva localidad de esta especie poco frecuente en el macizo de Segura-Cazorla, en el que sólo conocíamos las que recoge Salvo (1982: 193) en el Pantano del Tranco y en La Iruela. 